\title{
First report of tomato leaf curl New Delhi virus infecting muskmelon in India
}

\author{
Manmohan Dhkal $^{1} \cdot$ Abhishek Sharma $^{2} \cdot$ Gurpreet Kaur $^{2}$ \\ Received: 11 January 2020 / Accepted: 4 July 2020 / Published online: 13 July 2020 \\ (C) Società Italiana di Patologia Vegetale (S.I.Pa.V.) 2020
}

Keywords Muskmelon · Tomato leaf curl New Delhi virus · Yellowing and curling · India

During June 2018, severe symptoms of virus(es) and infestation of whitefly (Bemisia tabaci) were observed on muskmelon (Cucumis melo) crop in Patiala district of Punjab state. Fifteen per cent plants were found to be symptomatic, exhibiting severe yellowing and curling of leaves along with necrotic streaks symptoms on the fruits across seven hectare area surveyed. These symptoms resembled to the recently described infection of tomato leaf curl New Delhi virus (ToLCNDV) on melon (Trisciuzzi et al. 2018). DNA of eight symptomatic samples was subjected to PCR, with primer pair PALIc and PARIv (Rojas et al. 1993) yielded $\sim 1280$ bp product in all the samples. To further identify the associated begomovirus species, PCR amplicon was cloned in $\mathrm{pTZ57R/T}$ vector and sequenced. The sequence (MH939186) from infected sample analyzed by BLASTn tool showed $98.3 \%$ nucleotide similarity with ToLCNDV (AY939926) infecting Luffa cylindrica and 95\% with ToLCNDV (U15015) infecting tomato in India. The coat protein showed $97.8 \%$ amino acid identity with ToLCNDV accession No. MH-845616 and KT-965856 identified from Ludhiana and New Delhi, respectively. Primer pairs specific for the detection of major tomato leaf curl begomoviruses viz. tomato leaf curl New Delhi virus (ToLCNDV), tomato leaf curl Gujarat virus (ToLCGV), tomato leaf curl Karnataka virus (ToLCKV) and tomato leaf curl Bangalore virus (ToLCBV) were tested (Reddy et al. 2005) but only primer pair CRNDv30 and CRNDc1181, specific for ToLCNDV amplified specific product of 1180 bp in all eight samples, reconfirming their association with ToLCNDV. To the best of our knowledge, this is the first report of infection of ToLCNDV from muskmelon in India.

Acknowledgements Authors are thankful to DST, Govt. of India for INSPIRE fellowship to1st author and facilities created under PURSE and FIST programme.

\section{References}

Reddy RVC, Colvin J, Muniyappa V, Seal S (2005) Diversity and distribution of begomoviruses infecting tomato in India. Arch Virol 150: 845-867

Rojas MR, Gilbertson RL, Russell DR, Maxwell DP (1993) Use of degenerate primers in the polymerase chain reaction to detect whitefly transmitted geminiviruses. Plant Dis 77:340-347

Trisciuzzi N, Silletti MR, Gallitelli D, Spano R (2018) First detection of tomato leaf curl New Delhi virus in melon and zucchini squash in southern Italy. J Plant Pathol 100:149

Manmohan Dhkal

manmohan90@pau.edu

1 Department of Plant Pathology, Punjab Agricultural University, Ludhiana 141004, India

2 Department of Vegetable Science, Punjab Agricultural University, Ludhiana 141004, India 